\title{
Complex Dose Related Ketamine Analgesic, Antidepressant, Anesthetic and Toxic Mechanisms of Actions
}

\author{
Edward F. Domino, Mika Hirasawa-Fujita
}

Pharmacology, University of Michigan, USA

\section{Objective}

Describe in vitro/in vivo concentration-effects of ketamine, its enantiomers and metabolites.

Background

Fifty-three years have passed since racemic ketamine was first given to humans as an anesthetic agent. Lodge and his colleagues (1985) demonstrated that dissociative anesthetics such as phencyclidine and ketamine antagonize the excitatory actions of glutamic acid. Ketamine blocked the NMDA glutamate receptor as its mechanism of action.

Methods

Depending upon the in vitro concentration and in vivo dose of ketamine, enantiomers and its metabolites, many additional mechanisms of actions have been described. These include non-NMDA glutamate receptors (AMPA), hyperpolarization activated cyclic nucleotide $(\mathrm{HCN})$ channels, nicotinic, muscarinic, cholinergic and monoaminergic neuromodulation (including serotonin and dopamine), delta and mu-opioid agonism/potentiation, nitric oxide/cGMP system, neurosteroids, and L-type Ca2+ channels.

Results

The concentration/effects of racemic ketamine range from $50-10,000 \mathrm{ng} / \mathrm{mL}(0.21-42.1 \mathrm{nmol} / \mathrm{ml})$ both in vitro and in vivo. After IV administration, anesthetic concentrations are greater than 2,000 with peak levels as high as 10,000 ng/ml. Patients return to consciousness $\sim 1,100 \mathrm{ng} / \mathrm{ml}$. Low dose ketamine has analgesic effects with plasma concentrations of $\sim$ $150 \mathrm{ng} / \mathrm{ml}$ via IV and as low as $40 \mathrm{ng} / \mathrm{ml}$ via oral administration, suggesting that the metabolites of ketamine are actively contributing to its analgesic and antidepressant effects. Given a preferential distribution of ketamine brain:plasma ratio of 6.5 , its concentration would be $\sim 227 \mathrm{ng} / \mathrm{ml}$ in brain. In vitro studies show a NMDAR antagonism Ki value of $\sim 190$ $\mathrm{ng} / \mathrm{ml}$ for S-(+)-ketamine and $\sim 360 \mathrm{ng} / \mathrm{ml}$ for $\mathrm{R}(-)$-ketamine. This is the only in vitro receptor found within this low concentration. Concentrations required in vitro for $50 \%$ inactivation are much higher for all other receptors.

Conclusions

Racemic ketamine, its two enantiomers and metabolites have many complex mechanisms of action depending upon their in vitro/in vivo concentrations. For low dose ketamine, its NMDA antagonism and glutamic acid plus monoaminergic release appear to be its major mechanisms of action. Compared to $S-(+)$-ketamine, the less potent anesthetic enantiomer $\mathrm{R}(-)$-ketamine requires additional study for its analgesic and antidepressant effects. The metabolites of ketamine especially 2,6-hydroxynorketamine need more basic and clinical studies. 